\title{
Environmental Values and Authoritarianism
}

\author{
Michael Wiseman \\ Bavarian Academy of Sciences \\ and Humanities, Garching, Germany
}

\author{
Glenn Wilson \\ University of London, London,
}

UK

\author{
Franz X. Bogner \\ University of Bayreuth, Bayreuth, \\ Germany
}

\begin{abstract}
The present study examines relationships between the environmental values of P (preservation) and U (utilization) as measured by the 2-MEV(2-Factor Model of Environmental Values) scale (Wiseman \& Bogner, 2003; Bogner \& Wiseman, 2006), and authoritarianism, measured as a factor extracted from a shortened set of items adapted from the Wilson-Patterson conservatism scale (Wilson \& Patterson, 1968; Wilson, 1973). Respondents were 368 university students of Southern Germany. The study reports a negative correlation between authoritarianism and preservation and a positive correlation between authoritarianism and utilization. This result is interpreted in terms of the aggressive and self-serving nature of those scoring high on the tough-minded brand of conservatism assessed by the authoritarianism factor.
\end{abstract}

Keywords: environmental values, utilization, preservation, sets of attitudes, authoritarianism

\section{Introduction}

Although attitudes towards ecology and the environment are of increasing interest in times of fossil fuel depletion and a threatened global warming crisis, research on the way in which environmental attitudes fit within the realm of social attitudes in general has produced inconsistent findings. Iwata (1977), working in Japan, demonstrated a distinction between authoritarianism and conservatism in this arena. Although these two personality factors were moderately correlated $(r=0.41)$, they were related in opposing fashion to environmental attitudes: Authoritarianism was associated with negative attitudes to environmental concerns, while conservatism (measured by a Wilson-Patterson type scale) went with positive environmental attitudes.

Most subsequent studies have supported the former of these two findings that right-wingers express negative views of environmentalism. Van Liere and Dunlap (1980), reviewing evidence up until that time, found "substantial support for the hypothesis that liberals are more environmentally concerned than conservatives", while Hodgkinson and Innes (2000) found that "Social conservatism inhibited environmental beliefs". Peterson, Doty, and Winter (1993) reported the hostility of authoritarians towards the environmental movement. Forgas and Jolliffe (1994) also found that "greenies" generally had "radical political views" and were less likely to be religious, except for a small group of fundamentalists warning of extreme "doomsday" scenarios.

The present research was intended to clarify the relationship between broad social attitudes and environmental concerns using a relatively new instrument for quantifying environmental values, the 2-MEV (2-Factor Model of Environmental Values) scale (Bogner \& Wiseman 1999, 2002, 2006; Wiseman \& Bogner, 2003). This test captures two theoretically orthogonal higher-order factors: P (preservation), an ecocentric

Michael Wiseman, Leibniz Supercomputing Centre, Bavarian Academy of Sciences and Humanities.

Glenn Wilson, Institute of Psychiatry, Kings College, University of London.

Franz X. Bogner, Centre of Maths \& Science Education (Z-MNU), University of Bayreuth. 
factor reflecting conservation and protection of the environment, and $U$ (utilization), an anthropocentric factor reflecting the view that natural resources exist for humans to exploit. Numerous and extensive studies based on large samples led to the development of the 2-MEV model (Bogner \& Wilhelm, 1996; Bogner \& Wiseman, 1996, 1997, 1998, 1999, 2002a; 2002b, 2006). Other groups have confirmed this two-factor model (Milfont \& Duckitt, 2004; 2006), and the scale has been successfully employed in a variety of intervention studies (Bogner, 1998, 1999, 2004; Bogner \& Wiseman, 2004; Johnson \& Manoli, 2008). Further cross-validation studies include those of Bogner, Brengelmann, and Wiseman (2000), who examined the relationship between environmental attitudes and risk-taking behavior, and Wiseman and Bogner (2003) who studied the relationship with personality factors.

The instrument chosen to measure social attitudes was the Wilson-Patterson C (conservatism) scale (Wilson \& Patterson, 1968; Wilson, 1975). This was conceived as a measure of a general factor hypothesized to underlie social attitudes in all areas much as "g" (general intelligence) accounts for the inter-correlations amongst various mental abilities (Wilson, 1973). The general factor notion has been confirmed in a variety of different cultures, both European and non-European, and its origins traced to a personality factor that is part genetic and that reflects the need to manage uncertainty and threat (Jost, Glaser, Kruglanski, \& Sulloway, 2003). An unusual feature of the scale is that a short-item format replaces the lengthy and leading statements used in many other attitude scales, such as the California F-scale. This item format has the advantage of reducing the effect of acquiescence and social desirability response sets that plagued many of the scale's predecessors (Wilson, 1985). Four factors were extracted from a 20-item subset of the original 50 items of the C-scale. One of these factors, labeled authoritarianism, correlated with environmental values.

\section{Sample}

After exclusion of respondents 26 years old and older, the data from 368 student participants of Southern German universities were available for analysis, 67.1\% female; mean age $22.12(S D=1.55)$, minimum 18.92 and maximum 25.92.

\section{Measures}

$\mathrm{P}$ and $\mathrm{U}$ were computed as mean scores of the appropriate items of the 2-MEV (2-major environmental values) questionnaire. The $\mathrm{C}$ scale was a German translation of a 20-item subset adapted from the original 50-item Wilson-Patterson questionnaire. Since nothing was known of its structure, the 20 items were subjected to principal component analysis. On the basis of a screen plot, four factors were selected, rotated via oblimin, and the resulting factor scores correlated with $\mathrm{P}$ and U. Significant correlations with $\mathrm{P}$ and $\mathrm{U}$ were found with only one of these factors, consisting of the six items shown with their corresponding factor loadings in Table 1. Although only 48 participants responded to all 20 conservatism items, 179 responded to the six items of interest, so a mean score for these participants was computed over the six items. We labeled this score "authoritarianism", although the item content of this sub-factor suggests that "tough-mindedness" would be an equally apt descriptor, since it focuses on ethnocentrism and punitiveness, with an absence of items concerning religious puritanism or anti-hedonism, as are included in fuller versions of the C-scale. 
Table 1

Conservatism Items and Loadings

\begin{tabular}{ll}
\hline Item & Loading \\
\hline Superiority of the white race & 0.63 \\
Imperialism & 0.61 \\
Death penalty & 0.56 \\
Strict discipline & 0.54 \\
Patriotism & 0.54 \\
Censorship & 0.42 \\
\hline
\end{tabular}

\section{Statistical Methods}

Scores derived from the questionnaires are mean values, and hence the central limit theorem permits us to assume normality and employ parametric tests. Mean gender differences were examined using the independent sample $t$-test for unequal variances. Correlations were examined using Pearson's $r$. Gender differences in correlations of $\mathrm{C}$ with $\mathrm{P}$, and $\mathrm{C}$ with $\mathrm{U}$ were tested using the general linear model to realize a univariate ANOVA (analysis of variance) with the dependent variable $\mathrm{P}$ or $\mathrm{U}$ respectively, independent variable gender, covariate $\mathrm{C}$.

\section{Results}

Female respondents yielded a significantly higher mean score on preservation (mean $=3.814, S D=0.477$ ) than males (mean $=3.620, S D=0.594$ ): $t=3.088, d f=193.197, p=0.002$ (see Figure 1 ). In the case of $\mathrm{U}$, the difference was reversed, females yielding a significantly lower mean score (mean $=2.037, S D=0.458$ ) than males (mean $=2.200, S D=0.587$ ): $t=2.883, d f=189.066, p=0.009$. The mean C-score of females (mean $=$ $0.188, S D=0.187$ ) was significantly lower than that of males (mean $=0.331, S D=0.249): t=4.095, d f=$ 113.16, $p<0.001$ ) (see Figure 2). Women tend to be more religious and anti-hedonistic, thus balancing overall conservatism scores in the original C-scale (Wilson, 1975).

This gender effect in P or U is in line with previous studies (Bogner \& Wiseman, 2002; 2004). P and U are measured on 5-point Likert scales, hence the corresponding observed mean differences are of scant substantive interest, and essentially corroborate those earlier findings: 0.194 (3.8\%) in the case of P, $0.163(3.3 \%)$ in the case of U. The mean difference in C-scores of 0.143 (14.3\%) is considerably larger (see Figures 1 and 2).

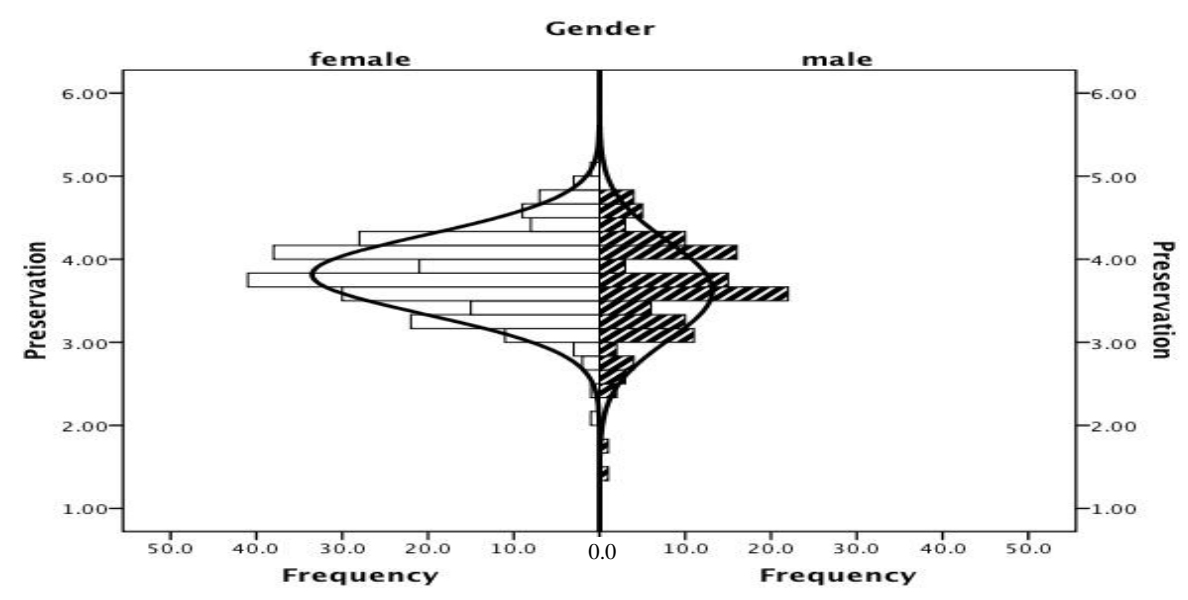

Figure 1. Gender differences in preservation. 


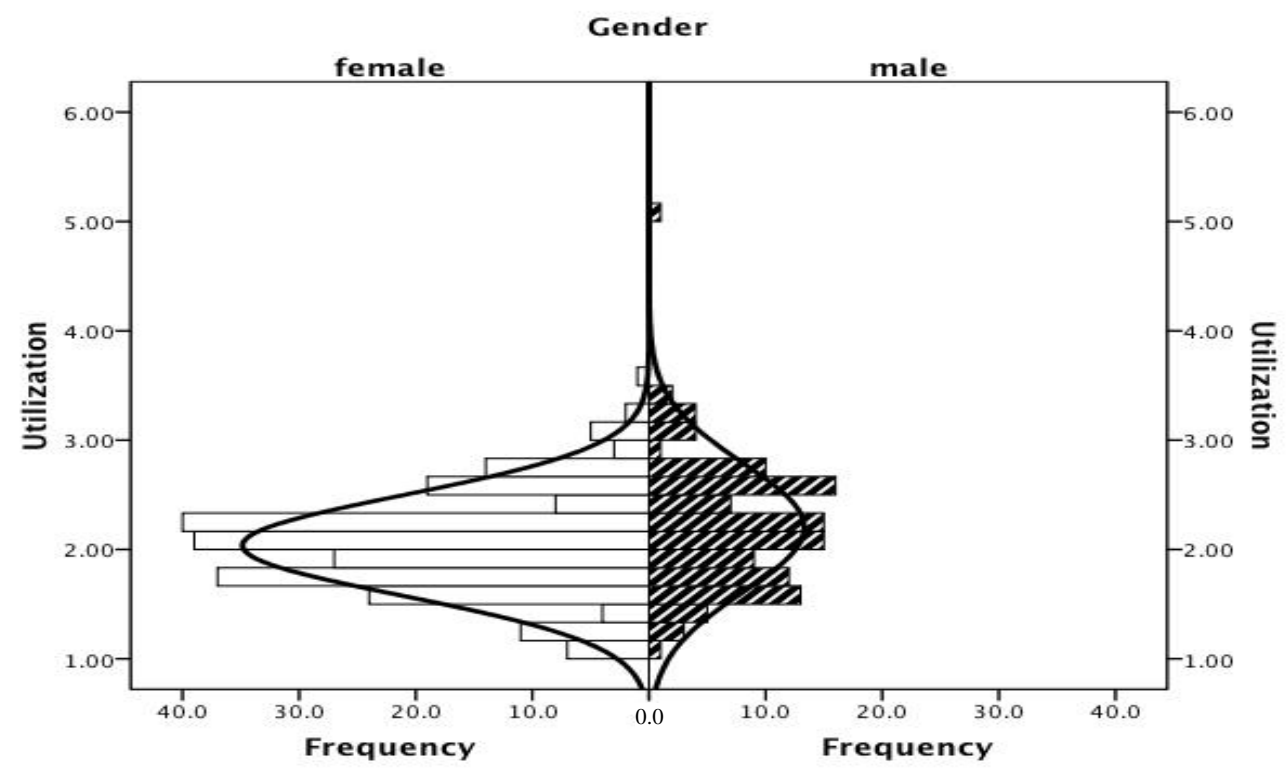

Figure 2. Gender differences in utilization.

Significant and substantive gender differences were found in the correlations between $\mathrm{C}$ and $\mathrm{P}(F=5.298$; $d f=1.176 ; p=0.023)$ and $C$ and $U(F=1.084 ; d f=1.47 ; p=0.046)$. Neither correlation observed for female respondents reached significance $\left(r_{\mathrm{c}, \mathrm{p}}=-0.111\right.$, n.s.; $\left.r_{\mathrm{c}, \mathrm{u}}=0.131\right)$; both correlations for males were significant $\left(r_{\mathrm{c}, \mathrm{p}}=-0.377, p=0.002 ; r_{\mathrm{c}, \mathrm{u}}=0.422, p<0.001\right)$ (see Figures 3 and 4$)$.

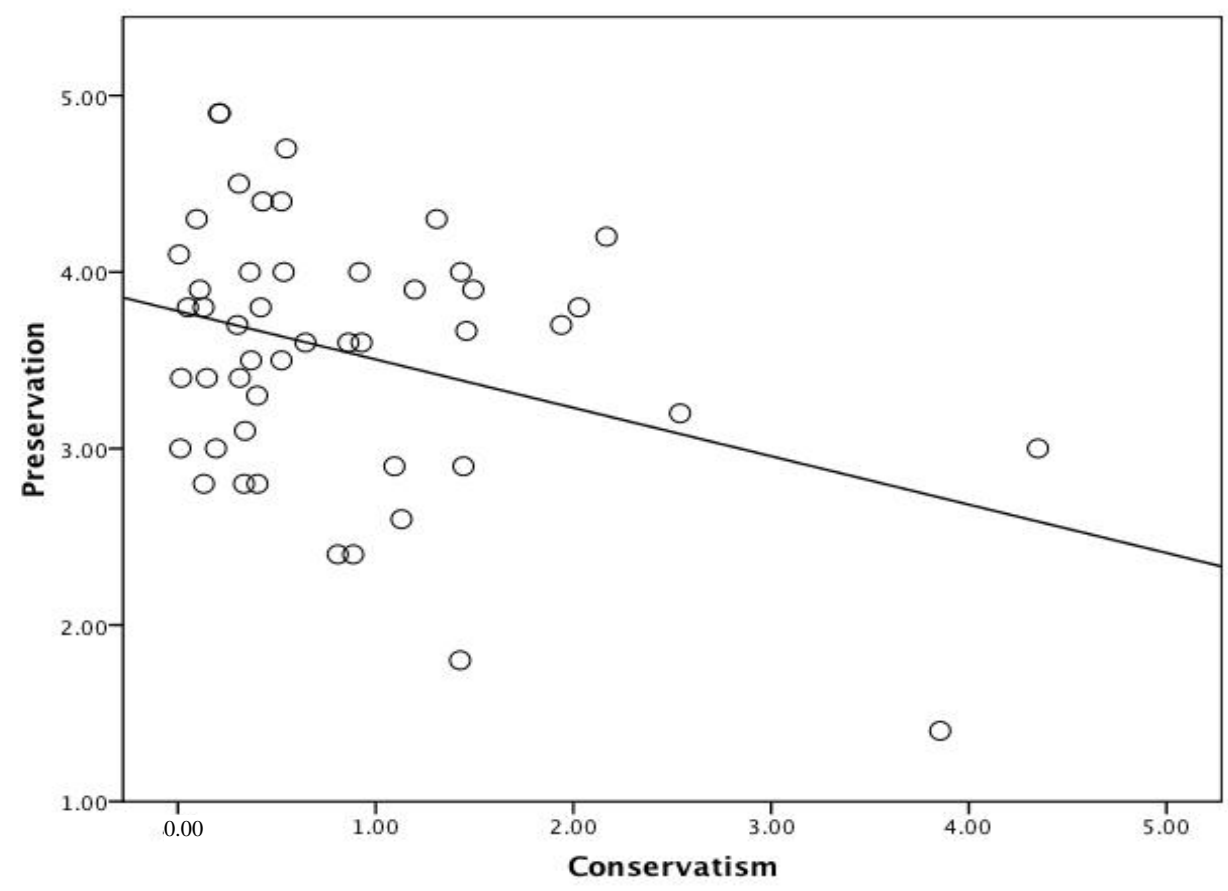

Figure 3. Scatterplot and regression of authoritarianism on preservation. 


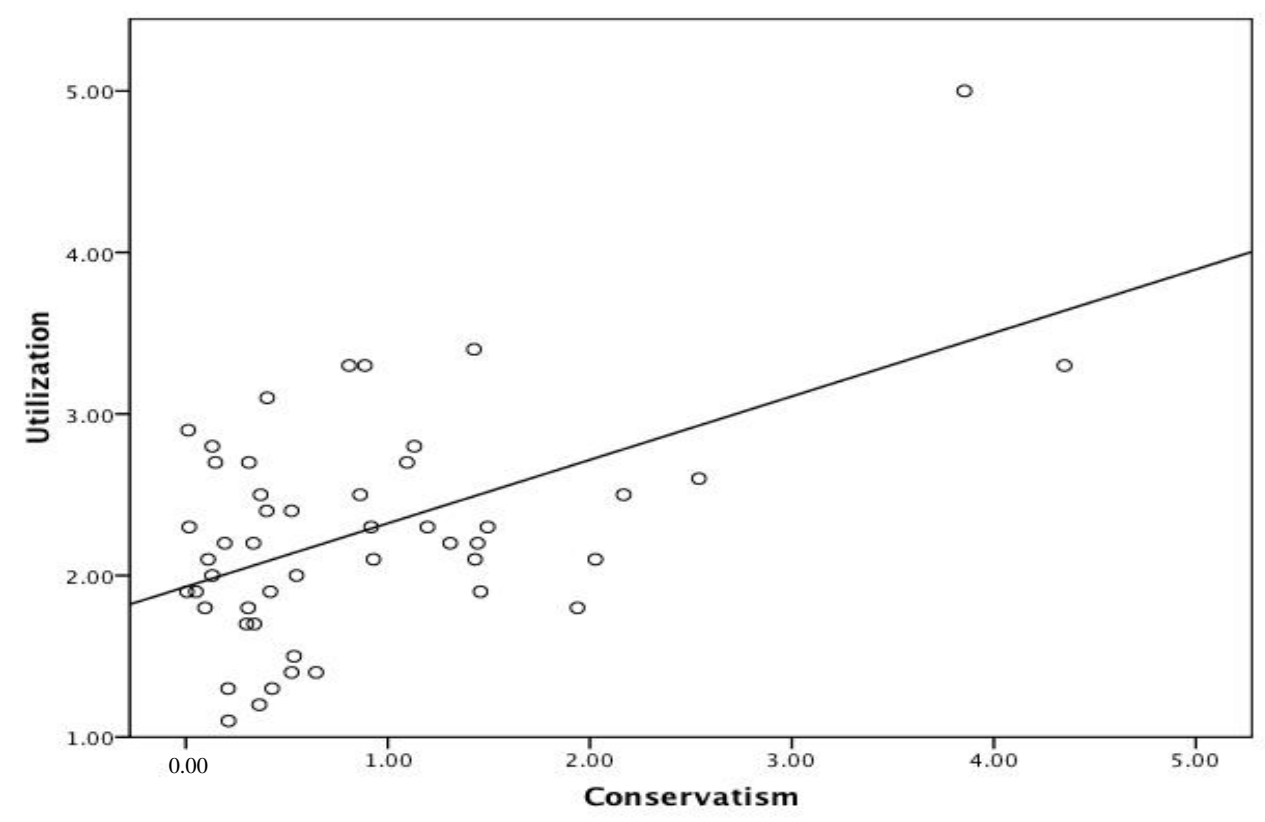

Figure 4. Scatterplot and regression line of authoritarianism on utilization.

\section{Discussion}

The youngest participant in the present study was almost 19, the oldest almost 26 years old. How well a scale developed for adolescents can be expected to perform on a sample so much older is debatable, although the 2-MEV has been confirmed using samples of university students (Milfont \& Duckitt, 2004; 2006) and in-service teachers as well (Munoz et al., 2009), however, in studies based on scores derived from a variety of scales.

The administrators of the test battery reported considerable annoyance on the part of the participants to the lack of an "undecided" response category in the short version of conservatism scale used here. This perhaps explains the large percentage of missing responses: $87 \%$ (320 of 368) of participants failed to complete the C-scale in full, in contrast to $0 \%$ missing responses to the $2-\mathrm{MEV}$ scale, and $2.4 \%$ missing responses to the gender item.

The central interest of the present paper lies in the relationship between authoritarianism on the one hand, preservation and utilization on the other hand. The first striking result is that only male respondents show any relationship between environmental values and authoritarianism. In the case of males, $\mathrm{C}$ is negatively related to P and positively to U. This substantiates the finding of Powell and Stewart (1978) of a clear positive correlation between anthropocentricism and conservatism in children aged eight to 15, and other studies mentioned in the introduction.

Interestingly, Wiseman and Bogner (2003) found that psychoticism, too, was negatively related to P ( $r=$ -0.25, $p<0.001)$ and positively to $\mathrm{U}(r=0.23, p<0.001)$. The possible relationship between $\mathrm{C}$ and Psychoticism suggested by our result has some support (Pearson \& Greatorex, 1981; Wilson \& Brazendale, 1973) and it is likely that authoritarianism as defined in the present paper (featuring as it does rather tough and hostile attitudes, such as ethnocentrism and punitiveness) may be even more strongly associated with P. If indeed, "toughness" is central to the form of conservatism tapped here, this might account for the apparent 
hostility of high $\mathrm{C}$ individuals to conservation and protection of the environment, combined with their view that nature is there to be exploited. It implies a kind of aggressive selfishness, in which control of other people and the environment is paramount and "to hell with any long-term consequences".

\section{Summary and Conclusions}

A number of studies have suggested that concern with environmental issues is related to liberal political views and attitude profiles. This study extends those findings by showing that this correlation applies to both the factor of $\mathrm{P}$, referring to conservation and protection of the environment, and $\mathrm{U}$ with conservative individuals being more likely to take the view that natural resources exist for humans to exploit. These relationships achieved significance only for males, though it is not clear why. The particular short-form of the C-scale used here reflected a sub-factor that was weighted toward ethnocentric and punitive items, hence tells us little about how other aspects of conservatism, such as religiosity and anti-hedonism might connect with environmentalism.

\section{References}

Bogner, F. X. (1998). The influence of short-term outdoor ecology education on long-term variables of environmental perspective. Journal of Environmental Education, 29(4), 17-29.

Bogner, F. X. (1999). Empirical evaluation of an educational conservation programme introduced in Swiss secondary schools. International Journal of Science Education, 21, 1169-1185.

Bogner, F. X. (2002) The influence of a residential outdoor education programme to pupil's environmental perception. Journal of Psychology of Education, 17(1), 19-34.

Bogner, F. X., \& Wilhelm, M. G. (1996). Environmental perception of pupils: Development of an attitude and behavior scale. Environmentalist, 16, 95-110.

Bogner, F. X., \& Wiseman, M. (1996). Environmental perception of Danish and Bavarian pupils: Towards a methodological framework. Scandinavian Journal of Educational Research, 41, 53-71.

Bogner, F. X., \& Wiseman, M. (1997). Environmental perception of rural and urban pupils. Journal of Environmental Psychology, $17,111-122$.

Bogner, F. X., \& Wiseman, M. (1998). Environmental perception of Swiss and Bavarian pupils. Swiss Journal of Sociology, 24, 547-566.

Bogner, F. X., \& Wiseman, M. (1999). Towards measuring adolescent environmental perception. European Psychologist, 4, 139-151.

Bogner, F. X., \& Wiseman, M. (2002a). Environmental perception: Factor profiles of extreme groups. European Psychologist, 7 , 225-237.

Bogner, F. X., \& Wiseman, M. (2002b). Environmental perception of pupils from France and four European regions. Journal of Psychology of Education, 1(7\&1), 3-18.

Bogner, F. X., \& Wiseman, M. (2004). Outdoor ecology education and pupils' environmental perception in preservation and utilization. Science Education International, 15(1), 27-48.

Bogner, F. X., \& Wiseman, M. (2006). Adolescents' attitudes towards nature and environment: Quantifying the 2-MEV model. The Environmentalist, 26, 247-254.

Bonner, F. X., Brengelmann, J. C., \& Wiseman, M. (2000). Risk-taking and environmental perception. The Environmentalist, 20, 49-62.

Evans, G. W., Juen, B., Corral-Verdugo, V., Corraliza, J., \& Kaiser, F. G. (2007). Children’s cross-cultural environmental attitudes and self-reported behaviors. Children, Youth and Environments, 17(4), 128-143.

Forgas, J. P., \& Jolliffe, C. D. (1994). How conservative are greenies? Environmental attitudes, conservatism, and traditional morality among university students. Australian Journal of Psychology, 46, 123-130.

Hodgkinson, S. P., \& Innes, J. M. (2000). The prediction of ecological and environmental belief systems: The differential contributions of social conservatism and beliefs about money. Journal of Environmental Psychology, 20, 285-294.

Iwata, O. (1977). Some attitudinal determinants of environmental concern. Journal of Social Psychology, 103, 321-322. 
Johnson, B., \& Manoli, C. C. (2008). Using Bogner and Wiseman's model of ecological values to measure the impact of an earth education program on children's environmental perceptions. Environmental Education Research, 14, 115-127.

Jost, J. T., Glaser, J., Kruglanski, A. W., \& Sulloway, F. J. (2003). Political conservatism as motivated social cognition. Psychological Bulletin, 129, 339-375.

Machemer, P. L., Bruch, S. P., \& Kuipers, R. (2008). Comparing rural and urban children's perceptions of an ideal community. Journal of Planning Education and Research, 28, 143-160.

Milfont, T. L., \& Duckitt, J. (2004). The structure of environmental attitudes: A first- and second-order confirmatory factor analysis. Journal of Environmental Psychology, 24, 289-303.

Milfont, T. L., \& Duckitt, J. (2006). Preservation and utilization: Understanding the structure of environmental attitudes. Environment and Human Behavior, 7, 29-50.

Munoz, F., Bogner, F. X., Clement, P., \& Carvalho, G. S. (2009). Teachers' conceptions of nature and environment in 16 countries. Journal of Environmental Psychology, 29, 407-413.

Powell, G. E., \& Stewart, R. A. (1978). The relationship of age, sex and personality to social attitudes in children aged 8 to 15 years. British Journal of Social and Clinical Psychology, 17, 307-317.

Pearson, P. R., \& Greatorex, B. J. (1981). Do tough-minded people hold tough-minded attitudes? Current Psychology, 1, 45-48.

Peterson, B. E., Doty, R. M., \& Winter, D. G. (1993). Authoritarianism and attitudes toward contemporary social issues. Personality and Social Psychology Bulletin, 19, 174-184.

Van Liere, K. D., \& Dunlap, R. E. (1980). The social bases of environmental concern: A review of hypotheses, explanations, and empirical evidence. Public Opinion Quarterly, 181-197.

Wilson, G. D. (1973). The psychology of conservatism. Academic Press, London.

Wilson, G. D. (1975). Manual for the Wilson-Patterson attitude inventory. NFER Publishing Co., Windsor.

Wilson, G. D. (1985). The "catchphrase” approach to attitude measurement. Personality and Individual Differences, 6, 31-37.

Wilson, G. D., \& Brazendale, A. H. (1973) Social attitude correlates of Eysenck’s personality dimensions. Social Behaviour and Personality, 1, 115-118.

Wilson, G. D., \& Patterson, J. R. (1968). A new measure of conservatism. British Journal of Social and Clinical Psychology, 7 , 264-269.

Wiseman, M., \& Bogner, F. X. (2003). A higher-order model of ecological values and its relationship to personality. Personality and Individual Differences, 34, 783-794. 